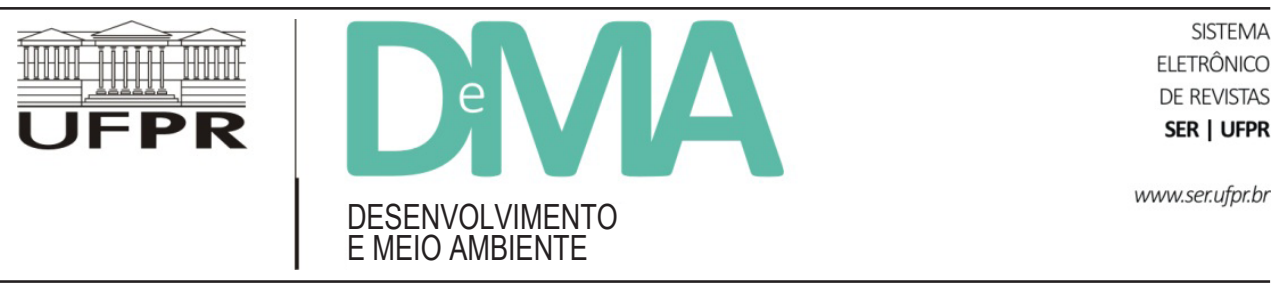

\title{
A perspectiva da mídia online sobre os acidentes entre veículos e animais em rodovias brasileiras: uma questão de segurança?
}

\section{The Online Media Perspective on Animal and Vehicle Accidents in Brazilian Highways: a Matter of Safety?}

\author{
Simone Rodrigues de FREITAS ${ }^{1 *}$, Leonardo Beltrão BARSZCZ1 \\ ${ }^{1}$ Universidade Federal do ABC (UFABC), Santo André, SP, Brasil. \\ *E-mail de contato: simonerfreitas.ufabc@gmail.com
}

Artigo recebido em 25 de junho de 2014, versão final aceita em 12 de setembro de 2014.

RESUMO: As colisões entre veículos e animais são um problema de segurança pública e de conservação da biodiversidade. Este estudo teve como objetivo avaliar os acidentes causados por colisões entre veículos e animais, analisando os animais envolvidos, o número de mortos e feridos, além da distribuição espacial e temporal desses acidentes no Brasil. Para tanto, utilizamos como método de amostragem notícias, disponíveis na internet, de acidentes entre veículos e animais registrados no Brasil no período de cinco anos. Analisamos 125 acidentes, que envolveram 135 animais, tendo como consequência 66 pessoas mortas, 166 feridos e 73 animais mortos. O principal resultado foi que a maioria dos acidentes envolveu animais domésticos, acarretando, principalmente, em pessoas feridas. No entanto, os acidentes com animais silvestres levaram mais pessoas a óbito, particularmente aqueles envolvendo capivaras. Além disso, discutimos as medidas mitigadoras mais adequadas e quais setores econômicos poderiam se interessar pelo tema.

Palavras-chave: ecologia de estradas; animais domésticos; animais silvestres; segurança; óbitos.

ABSTRACT: Wildlife-vehicle collisions are a concern for public security and biodiversity conservation. The purpose of this study is to evaluate the accidents caused by wildlife-vehicle collisions, analyzing the animals involved, the number of deceased and injured people, as well as the space and time distribution of accidents in Brazil. Therefore, we use as sampling method, news on accidents between vehicles and animals recorded in Brazil over a 5 years period, available on the web. We analyzed 125 accidents including 135 animals, 66 dead people, 166 injured people and 73 dead animals. The main result was that most of the accidents involved domestic animals, causing mainly injured people; however, accidents with wildlife caused more deceases, particularly involving capybaras. In addition, we discussed the most suitable mitigation measures and the economic sectors that could be interested in this issue.

Keywords: road ecology; domestic animals; wildlife; security; deaths. 


\section{Introdução}

A Ecologia de Estradas visa estudar os efeitos que as estradas podem causar em populações e em comunidades de plantas e de animais e encontrar soluções para evitar ou minimizar esses efeitos negativos (Forman \& Alexander, 1998; Forman et al., 2003; Coffin, 2007). As estradas podem modificar o solo, a hidrologia, os ecossistemas aquáticos, a vegetação e a fauna (Forman et al., 2003; Laurance et al., 2009). No caso da fauna, o efeito negativo mais facilmente observado nas estradas é a morte do animal devido à colisão com veículos (Laurance et al., 2009; Benítez-López et al., 2010; Van der Ree et al., 2011; Rosa \& Bager, 2013). Além da morte por atropelamento, outros mecanismos relacionados às características da rodovia que afetam a fauna são: evitação ("avoidance" em inglês) da rodovia, do ruído ou dos veículos; e, atração pela rodovia (Rosa \& Bager, 2013). Algumas espécies evitam atravessar as rodovias por causa do ruído ou da vibração no solo associados ao deslocamento dos veículos (Jaeger et al., 2005; Laurance et al., 2009), ou por causa do efeito de borda causado pelo contraste entre a superfície da rodovia e a vegetação nas margens desta, levando a alterações no microclima e na estrutura e composição da vegetação mais próxima da estrada (Murcia, 1995). Quando a espécie apresenta o comportamento de evitação em relação à estrada, sua população tende a ficar isolada nos fragmentos de habitat às margens dessa estrada (Jaeger et al., 2005; Laurance et al., 2009), esse isolamento reduz o fluxo gênico e pode levar à redução da diversidade genética e ao potencial risco de extinção, particularmente para espécies que normalmente são raras, seja por causa de sua distribuição geográfica restrita, seja devido à baixa abundância (Lande, 1993; Hanski, 1998; Purvis et al., 2000). No caso das espécies que atravessam a rodovia e são atropeladas por veículos, a quantidade e a frequência dos atropelamentos pode ser alta e contínua o suficiente para levar à redução das populações, o que reduz a diversidade genética e aumenta o risco de extinção da espécie, ao menos localmente (Balkenhol \& Waits, 2009; Jackson \& Fahrig, 2011). Além disso, os atropelamentos com animais de grande porte, silvestres ou domésticos, podem levar a acidentes graves com riscos à vida humana e altos custos econômicos, tornando-se também uma questão de segurança (Seiler, 2005; Huijser et al., 2009).

A perspectiva de segurança em relação às colisões entre veículo e animais é a principal justificativa para os monitoramentos de atropelamentos de fauna na América do Norte e na Europa e para a aplicação das consequentes medidas de mitigação, principalmente porque a frequência de acidentes com animais de grande porte resulta em muitas vítimas humanas e em altos custos para a sociedade (Seiler \& Helldin, 2006; Huijser et al., 2009). Na Suécia, são registradas 4.500 colisões entre veículos e alces (Alces alces) e 24.000 corças (Capreolus capreolus) em média por ano. Além disso, nota-se que colisões entre ungulados e veículos têm aumentado, provavelmente em resposta ao aumento do tráfego (Seiler, 2004). Nos Estados Unidos, estima-se que anualmente ocorrem 2 milhões de colisões entre veículos e mamíferos de grande porte, tendo como consequência 211 mortes de pessoas e mais de 29.000 feridos (Huijser et al., 2009). Em outro estudo nos EUA, mas em período diferente com base em registros do Conselho de Segurança Nacional ("National Safety Council"), ocorreram, em média, 165 mortes em 10 anos, sendo estimado um custo de mais de 1 bilhão de dólares com gastos médicos e com prejuízos materiais (Langley et al., 2006). Estima-se que os custos com danos materiais com o veículo e com ferimentos ou fatalidades humanas atinjam mais de 1 bilhão de euros por ano na Europa e de 23 milhões a 1 bilhão de dólares por ano nos Estados Unidos (Seiler \& Helldin, 2006; Huijser et al., 2009). A variação dos custos se deve a diferentes períodos de estudo e fontes de informação, mas são relevantes para se ter uma noção da ordem de grandeza dos prejuízos. Os custos envolvem despesa média do reparo do veículo, além de custos relacionados a ferimentos e a fatalidades humanas, reboque, assistência médica no local do acidente, investigação do acidente e remoção da carcaça do animal da rodovia (Huijser et al., 2009). Para reduzir as colisões entre veículos e animais, medidas mitigadoras são utilizadas, tais como: sinalização, redutores de velocidade, instalação de cercas ao longo da estrada e passagens de fauna (também chamadas de ecodutos ou faunodutos; Huijser et al., 2009; Laurance et al., 2009; Beckmann et al., 2010; Taylor \& Goldingay, 2010; Van der Grift et al., 2013). Quando os custos relacionados às colisões veículo-animal são altos, a instalação de passa- 
gens de fauna se torna economicamente atrativa para o governo ou para a empresa responsável pela rodovia e pela segurança dos usuários desta (Huijser et al., 2009).

No Brasil, o registro dos acidentes nas rodovias é feito pela Polícia Rodoviária, particularmente nas rodovias federais, estaduais e municipais. Os relatórios anuais possuem a informação sobre o tipo do acidente (ex. causado por atropelamento de animal) e o local do acidente (rodovia e km). Esse registro feito pela Polícia Rodoviária é a fonte oficial, com dados regularmente coletados, bem distribuídos nacionalmente e, por isso, uma das melhores formas potenciais de obter estimativas de acidentes envolvendo animais e suas consequências pelo território brasileiro. No entanto, uma falha do sistema é a falta de informação do animal envolvido no acidente, incluindo se este é doméstico ou silvestre. Sob a perspectiva econômica, essa informação é relevante para determinar o responsável pelo pagamento dos danos resultantes do acidente. No caso dos animais domésticos, o dono do animal é o responsável por mantê-lo em segurança. Perante a lei, caso um animal doméstico se envolva em um acidente, o dono é responsabilizado penalmente e deverá ressarcir o dano por este causado, se não provar culpa da vítima ou força maior (Código Civil, Lei no 10.406 de 10/01/2002, Livro I - Do Direito das Obrigações, Título IX - Da Responsabilidade Civil, Capítulo I - Da Obrigação de Indenizar, Art. 936). Além disso, tanto para animais domésticos quanto para animais silvestres, em trechos de rodovias fora do perímetro urbano, o proprietário da rodovia é o responsável por manter a segurança do usuário, evitando que o animal atravesse a rodovia ou removendo os animais da pista. Caso a rodovia esteja em regime de concessão para a iniciativa privada, o responsável é a empresa concessionária. Se a rodovia está sob administração pública, o responsável é o Estado. Em caso de acidentes em rodovias públicas, a Polícia Rodoviária deve ser acionada para registrar o acidente e gerenciar as medidas de emergência; já em trechos urbanos da rodovia, o órgão do governo responsável pela remoção do animal da pista é Centro de Controle de Zoonoses. Vale a pena ressaltar que a questão das responsabilidades é polêmica e as leis não são detalhadas o suficiente para resolver as questões de segurança, especialmente para animais silvestres.
Sob a perspectiva da conservação da biodiversidade, é importante saber quais espécies são mais atropeladas e quais os locais onde as colisões são mais frequentes para determinar as medidas mitigadoras mais adequadas (Beckmann et al., 2010). Para que os registros dos acidentes envolvendo animais nas rodovias públicas feitos pela Polícia Rodoviária sejam úteis sob a perspectiva da conservação, o ideal seria que cada registro contivesse, no mínimo, uma fotografia digital do animal atropelado para possibilitar a identificação por especialistas, além da informação do local (rodovia e km, ou coordenada geográfica obtida por GPS, datum WGS84, formato graus, minutos e segundos decimais) e data (dia, mês e ano) do acidente. Já nas rodovias em regime de concessão, existem funcionários que percorrem a rodovia $24 \mathrm{~h}$ em todos os dias da semana para fins de limpeza e de manutenção. Assim, para que os dados sejam utilizados para estudos de conservação, quando os funcionários encontram um animal atropelado, o ideal é que, pelo menos, as mesmas informações - fotografia, local e data - sejam registradas e disponibilizadas para futuras pesquisas.

Estimativas da taxa de animais atropelados nas rodovias brasileiras, incluindo dados de pesquisas científicas e de licenciamento ambiental para ampliação ou construção de novas rodovias, apontam para o mínimo de 14,7 milhões de animais vertebrados silvestres por ano, a maioria de pequeno ou médio porte (Dornas et al., 2012). Estimativas menos conservadoras sugerem que 475 milhões de animais selvagens são atropelados por ano no Brasil (CBEE, 2014a). A variação das estimativas se deve à escassez e à má distribuição dos dados obtidos em monitoramentos de animais atropelados nas rodovias brasileiras. Se dados mais completos fossem obtidos por monitoramentos intensivos e constantes, e depois disponibilizados, seria possível ter uma estimativa das colisões entre veículo e animal em escala nacional, tanto sob a perspectiva da segurança quanto da conservação da biodiversidade. Dessa forma, tanto a Polícia Rodoviária quanto as empresas concessionárias poderiam obter e disponibilizar esses dados. Outra iniciativa complementar para obter dados de atropelamento de animais silvestres em escala nacional é o aplicativo de celular desenvolvido e recém-lançado pelo Centro Brasileiro de Estudos em Ecologia de Estradas (CBEE), o sistema Urubu, em que 
qualquer pessoa que encontre um animal atropelado e que tenha um tablet/smartphone com GPS e máquina fotográfica pode enviar o registro para o Banco de dados brasileiro de Atropelamento de Fauna Selvagem (BAFS; CBEE, 2014b).

Como as informações sobre colisões entre veículos e animais, incluindo o tipo de animal (doméstico ou silvestre) e a espécie (ao menos o nome vulgar) não estão disponíveis neste momento na escala nacional, foram usadas as notícias publicadas na Internet sobre acidentes nas rodovias brasileiras envolvendo animais. Com a análise das notícias pretendemos obter uma amostragem com abrangência nacional da quantidade desse tipo de acidente e suas consequências para as vidas humanas. Dessa forma, o objetivo desse estudo foi avaliar os acidentes causados por colisões entre veículos e animais, analisando os animais envolvidos, o número de mortos e de feridos, além da distribuição espacial e temporal dos acidentes no Brasil. Não cabe aqui uma análise dos fatores que influenciam a mídia, mas temos consciência de que esse estudo possui um viés para acidentes graves com mortos, feridos ou veículos destruídos. Devemos pensar que, em geral, para se tornar notícia, ou seja, para um fato ser relevante sob a perspectiva da mídia, o acidente deve causar comoção popular. Por fim, algumas medidas mitigadoras são sugeridas particularmente para animais silvestres.

\section{Material e Métodos}

Um levantamento de notícias sobre acidentes com veículos envolvendo animais foi realizado usando o buscador da Internet da empresa Google (www.google.com. br). As palavras-chave usadas no levantamento tiveram como objetivo incluir animais, particularmente aqueles de médio e de grande porte que podem causar acidentes graves e que também são encontrados em monitoramentos de atropelamentos de animais silvestres (Dornas et al., 2012). As seguintes combinações de palavras-chave foram usadas: "rodovia + acidente+ animal", "estrada + colisão + animal", "estrada + colisão + capivara", "estrada + colisão + onça", "estrada + colisão + tamanduá", "estrada + colisão + cavalo", "estrada + colisão + boi", "estrada + colisão + javali", "estrada + colisão + cachor- ro" e "estrada + colisão + vaca". Espera-se que a maioria das notícias sobre acidentes envolvendo animais inclua ao menos uma dessas combinações de palavras-chave.

Dos registros obtidos, foram selecionadas apenas notícias de acidentes ocorridos no Brasil, publicadas na Internet no período de cinco anos, entre janeiro de 2007 e fevereiro de 2012. Para cada notícia encontrada foram extraídas as seguintes informações sobre o acidente: data da notícia e do acidente, animal envolvido na colisão com o veículo, estado do animal (se sobreviveu ou não ao acidente), número de feridos, número de mortos, veículo envolvido, estado do veículo (ex. perda total), rodovia e estado do acidente. Foram retiradas das análises as notícias repetidas e as que não possuíam as referidas informações. No caso das que apresentavam apenas a data da publicação, considerou-se que o acidente ocorreu no dia anterior.

\section{Resultados}

Abordando o período analisado de cinco anos, foram avaliadas 125 notícias sobre acidentes, ocorridos no Brasil, envolvendo veículos e animais.

\subsection{Animais envolvidos e consequências sobre vidas humanas}

Das notícias analisadas, 88 (70\%) envolveram animais domésticos (equinos, bovinos, javalis e cachorro) e 37 (30\%) envolveram animais silvestres (capivaras, tamanduás, tatus, sucuri e onça; Figura 1). A grande maioria é de mamíferos (99\%), tendo apenas um caso envolvendo répteis. Alguns desses acidentes envolveram mais animais, no caso dos equinos e das capivaras, totalizando 135 animais em 125 acidentes (Figura 1). Os acidentes tiveram como consequência 66 pessoas mortas, 166 pessoas feridas e 73 animais mortos (Figura 1). Os acidentes envolvendo animais domésticos, principalmente envolvendo equinos e bovinos, apresentaram maior mortalidade de animais $(53,73 \%)$ e um maior percentual de feridos entre as vítimas $(97,58 \%)$ do que aqueles com os animais silvestres (Figura 1). Por outro lado, os acidentes envolvendo animais silvestres 
acarretaram maior percentual de óbitos humanos (41, $62 \%$ ), principalmente os acidentes com as capivaras (Figura 1). Equinos, bovinos e capivaras foram os animais mais registrados em acidentes (acima da média dos grupos animais juntos, média $=15,0$ ) e também os que mais morreram devido à colisão com veículos (acima da média dos grupos animais juntos, média $=8,1$ ). Equinos e capivaras se envolveram em acidentes que causaram mais óbitos (acima da média dos grupos animais juntos, média $=7,3)$, representando $73 \%$ dos óbitos humanos. Acidentes envolvendo esses dois grupos animais e bovinos resultaram em mais pessoas feridas (acima da média dos grupos animais juntos, média $=18,4)$, representando $86 \%$ dos feridos. Vinte e quatro feridos (14\% do total) e cinco óbitos ( $8 \%$ do total) foram consequências de acidentes sem colisão com o animal, quando o motorista tentou desviar do animal e perdeu o controle do veículo, particularmente com metade dos tamanduás, todos os tatus e a onça que não foram encontrados (Figura 1).

\subsection{Veículos envolvidos e horário do acidente}

\subsubsection{Tipo de veículo}

A maioria dos animais domésticos $(61 \%)$ e dos silvestres (63\%) foram registrados em acidentes noticiados com um ou mais carros, ou automóveis de passeio (Figura 2A). Os acidentes envolvendo um ou mais carros foram os mais frequentemente noticiados (60\%), resultaram em mais mortos (59\%) e mais feridos (64\%; Figura 2A). Além dos acidentes com um ou mais carros, aqueles com uma motocicleta envolveram mais animais domésticos $(20,21 \%)$ e mais silvestres $(6,15 \%)$ do que a média (11,9 e 5,0 respectivamente). Acidentes com uma motocicleta também resultaram em mais mortos $(11,17 \%)$ e em mais feridos $(21,13 \%)$ do que a média (8,3 e 20,8 respectivamente). Os acidentes envolvendo diversos tipos de veículos envolveram mais animais

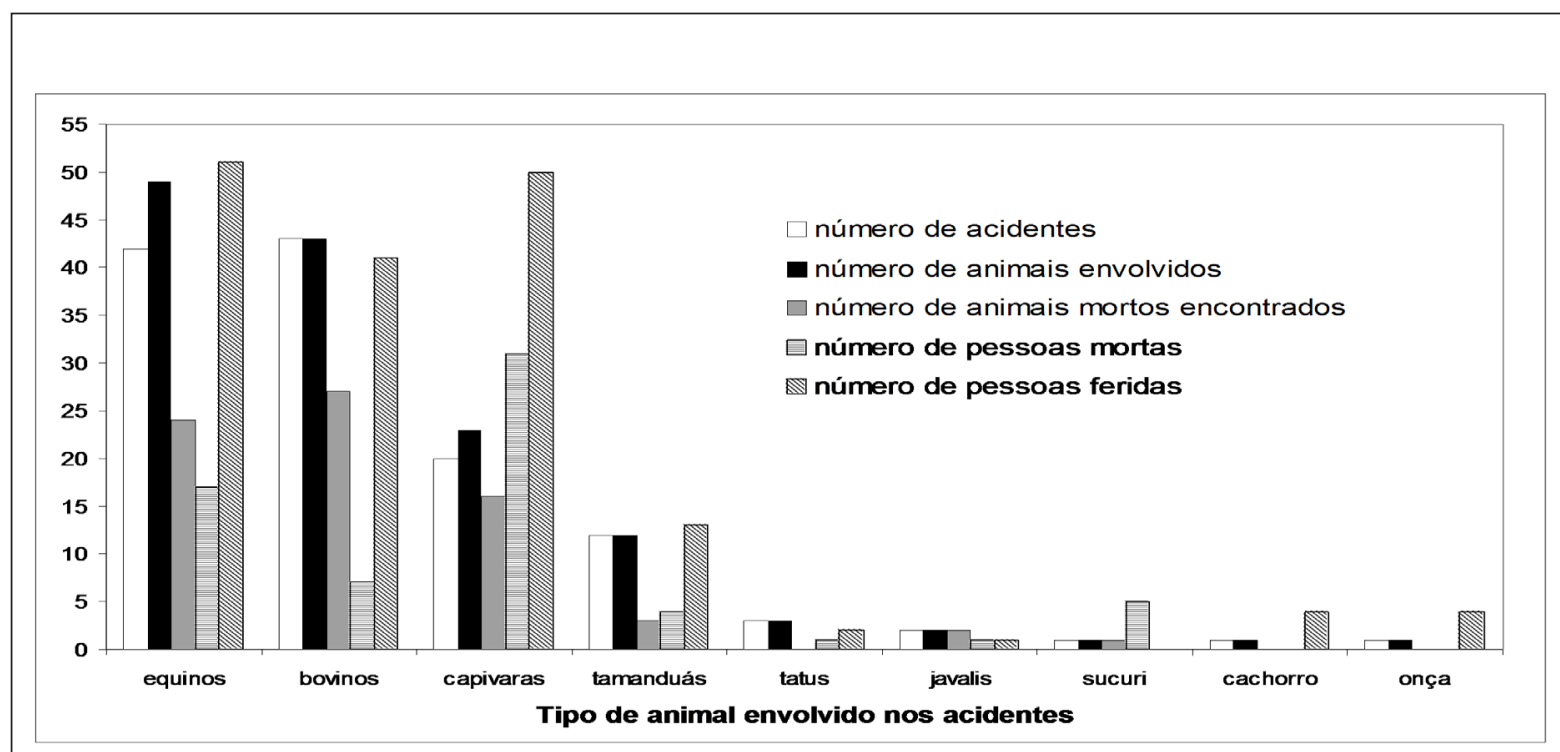

FIGURA 1 - Número de acidentes e consequências sobre os animais e pessoas por grupo animal: domésticos (equinos, bovinos e cachorro), silvestres nativos (capivaras, tamanduás, tatus, sucuri e onça) e silvestre exótico/doméstico (javalis). 
silvestres $(6,15 \%)$ do que a média $(5,0)$, e resultaram em mais mortos $(14,21 \%)$ e mais feridos $(33,20 \%)$ do que a média (8,3 e 20,8 respectivamente; Figura 2A).

\subsubsection{Periodo em que ocorreu o acidente}

Apesar de 37\% das notícias não informar o período ou a hora do acidente, pôde-se perceber que a maioria dos casos, em que foi possível fazer essa avaliação, ocorreu à noite ou de madrugada $(68,54 \%$; Figura $2 \mathrm{~B})$. Os acidentes envolvendo animais domésticos e silvestres que ocorreram à noite $(25 \% \mathrm{e} 38 \%$ respectivamente $)$ ou de madrugada ( $24 \%$ e $23 \%$ respectivamente) foram acima da média (19,0 domésticos e 8,0 silvestres; Figura 2B). Os acidentes que resultaram em mortos e feridos que ocorreram à noite $(27 \%$ e $37 \%$ respectivamente) e de madrugada (29\%) foram acima da média (13,2 mortos e 33,2 feridos; Figura 2B).

\subsubsection{Quantidade de veículos envolvidos no acidente}

A maioria dos acidentes envolveu apenas um veículo e pelo menos um animal (70\%), envolvendo mais animais domésticos $(62,65 \%)$ e silvestres $(27,68 \%)$ do que a média (19,0 e 8,0 respectivamente), e resultaram em mais mortos $(35,53 \%)$ e feridos $(91,55 \%)$ do que a média (13,2 e 33,2 respectivamente; Figura 2C). Os acidentes com dois veículos e pelo menos um animal ( $22 \%$ dos acidentes) envolveram mais animais silvestres $(11,28 \%)$ do que a média $(8,0)$, e resultaram em mais mortos $(30,45 \%)$ e feridos $(46,28 \%)$ do que a média (13,2 e 33,2 respectivamente; Figura 2C). Vale notar que um acidente envolvendo cinco veículos (1 motocicleta, 1 caminhão e 3 carros) e uma capivara resultou em 13 feridos em uma rodovia de São Paulo em Abril de 2008 (Figura 2C).

\subsubsection{Condições do veículo depois do acidente}

A maioria das notícias não informou o estado do veículo após o acidente (62\%). No entanto, observa-se que os animais domésticos se destacam nos danos na parte dianteira $(12,13 \%)$ e em veículos muito danificados $(14,15 \%)$, enquanto os animais silvestres se destacam nos veículos com perda total (10,25\%). Dos 14 acidentes registrados com perda total, 8 envolveram 10 animais silvestres: 1 tatu, 1 sucuri, 2 tamanduás e 6 capivaras (sendo 3 em um mesmo acidente envolvendo um carro e um ônibus, acarretando 5 mortos e 11 feridos em uma rodovia no Paraná em junho de 2011). Os acidentes envolvendo veículos com perda total apresentaram mais mortos $(17,26 \%)$ e feridos $(42,25 \%)$ do que a média (16,5 e 41,5 respectivamente; Figura 2D).

\subsection{Distribuição dos acidentes por estado bra- sileiro}

A distribuição dos acidentes envolvendo veículos e animais pelos estados brasileiros mostra que a maioria das notícias envolvendo acidentes com animais domésticos está em São Paulo e no Paraná (Figura 3A), já os que envolvem animais silvestres estão em São Paulo e no Mato Grosso do Sul (Figura 3D). Seis estados registraram mais animais domésticos do que a média $(5,3)$ : São Paulo, 35; Minas Gerais, 11; Rondônia, 7; Paraná, 7; Rio Grande do Sul, 6; e, Acre, 6 (Figura 3A). Os equinos estiveram envolvidos em mais acidentes do que a média $(4,1)$ em São Paulo (22), em Minas Gerais (8) e na Bahia (5; Figura 3B). Os bovinos sofreram mais acidentes do que a média $(4,3)$ em São Paulo (12), em Rondônia (7), no Rio Grande do Sul (5) e no Acre (5; Figura 3C). Quatro estados registraram mais animais silvestres do que a média (2,2): Mato Grosso do Sul (12); São Paulo, 10; Paraná, 4; e, Santa Catarina, 4 (Figura 3D). As capivaras foram envolvidas em mais acidentes do que a média $(3,3)$ em São Paulo (9) e no Paraná (4; Figura 3E). Os tamanduás sofreram mais acidentes do que a média $(2,4)$ em Mato Grosso do Sul $(7$; Figura 3F). 


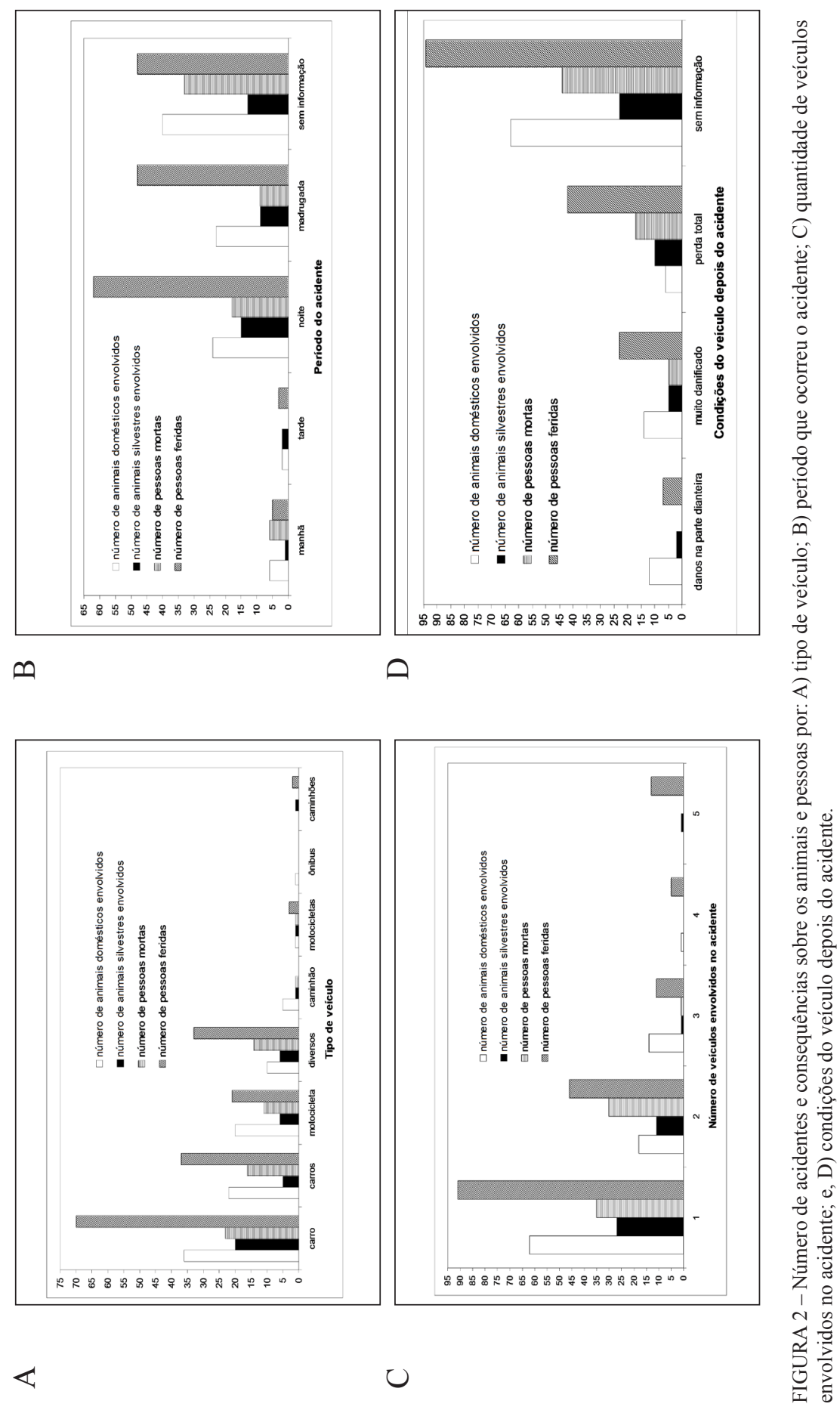


A

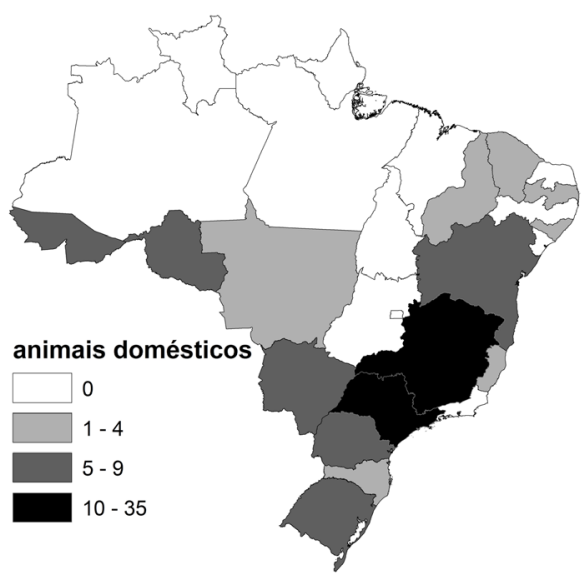

$\mathrm{C}$

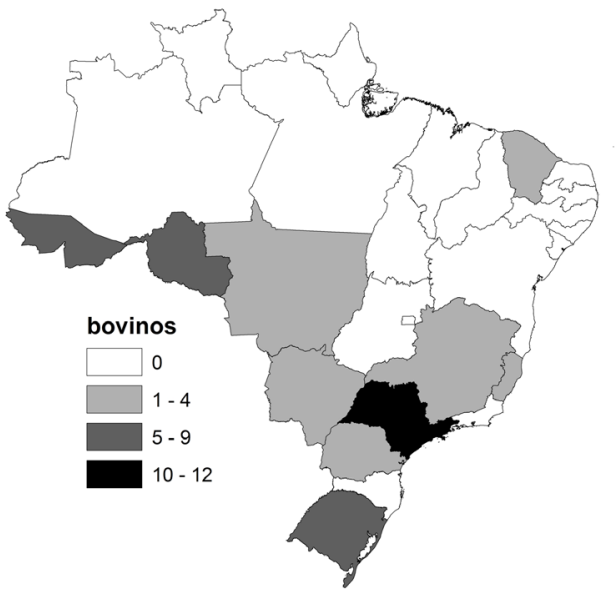

$\mathrm{E}$

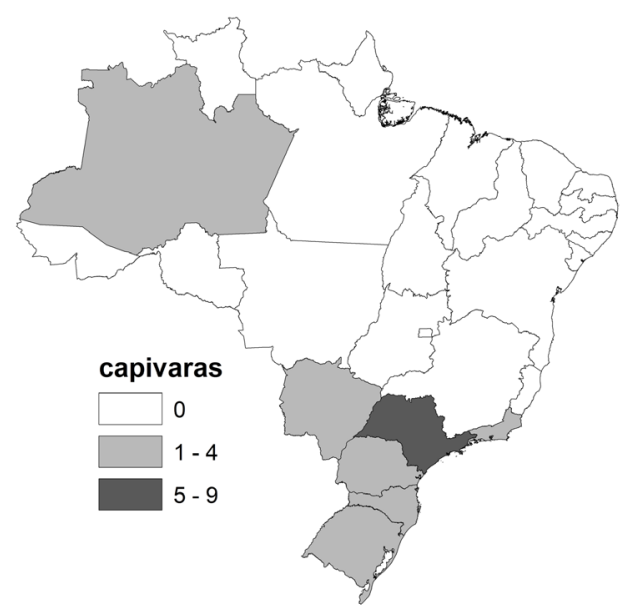

B

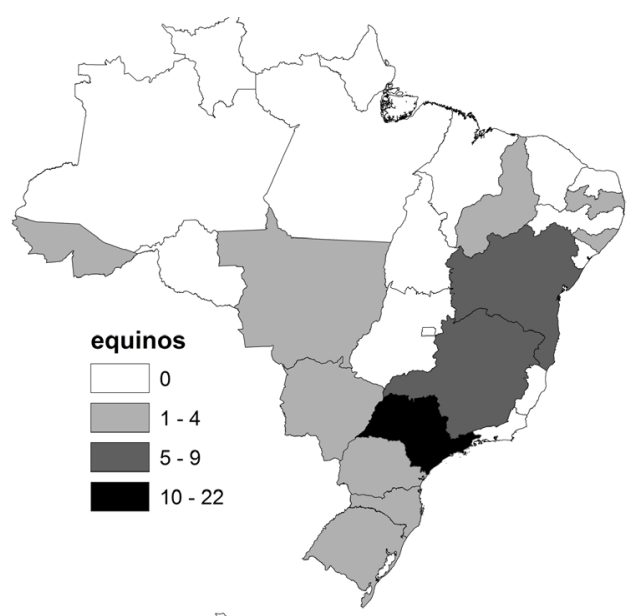

$\mathrm{D}$

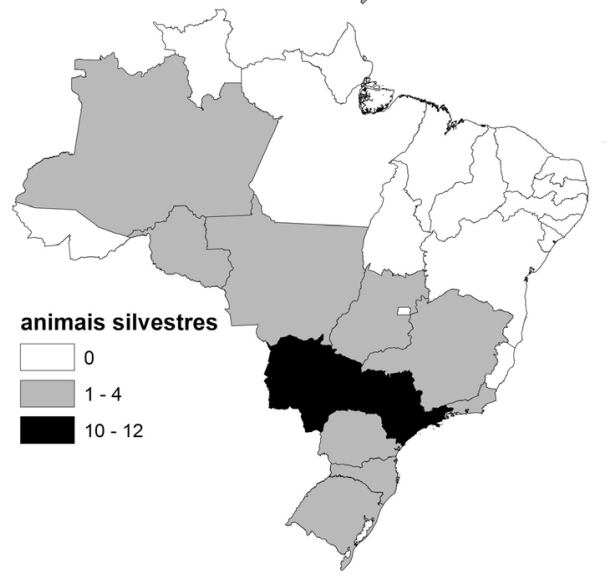

$\mathrm{F}$

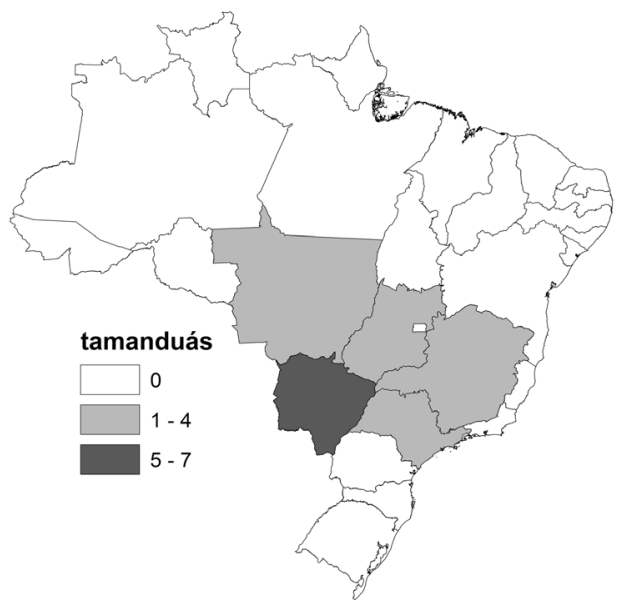

FIGURA 3 - Número de acidentes envolvendo animais por estado brasileiro: A) animais domésticos; B) equinos; C) bovinos; D) animais silvestres; E) capivaras; e, F) tamanduás. 


\subsection{Distribuição dos acidentes nos cinco anos}

As notícias sobre acidentes entre veículos e animais vêm aumentando nos últimos anos, sendo observado um aumento acima da média (domésticos 4,5 e silvestres 1,9) a partir do período de setembro a novembro de 2010 , período que concentrou $88 \%$ das notícias e $89 \%$ dos acidentes noticiados (Figura 4). Os animais domésticos envolvidos em acidentes foram mais noticiados no período de dezembro de 2011 a fevereiro de 2012 (28, 29\%), sendo representados principalmente pelos equinos (20, $41 \%$; Figura 4). Os acidentes com bovinos foram mais frequentes $(15,35 \%)$ no período de setembro a novembro de 2011 (Figura 4). Os acidentes com animais silvestres foram mais noticiados $(12,30 \%)$ no período de junho a agosto de 2011, sendo representados principalmente pelas capivaras $(7,30 \%$; Figura 4$)$.
As notícias mais antigas (2007 a 2008) são de acidentes com animais domésticos (3, 3\%) e silvestres (2, $5 \%$ ) em São Paulo e Mato Grosso do Sul (Figuras 5A1 e 5A2). Nos dois anos seguintes, 2009 e 2010, mais estados noticiaram acidentes com animais domésticos $(15,16 \%)$, particularmente São Paulo (Figura 5B1), e com animais silvestres (10, 25\%; Figura 5B2). Nos últimos anos (de 2011 a fevereiro de 2012), as notícias se tornaram mais frequentes nos estados e novos estados passaram a noticiar os acidentes com animais nas rodovias, tanto para animais domésticos $(77,81 \%$; Figura $5 \mathrm{C} 1)$ quanto para animais silvestres $(28,70 \%$; Figura 5C2).

\section{Discussão}

A maioria dos acidentes noticiados entre veículos e animais envolveu animais domésticos com um eleva-

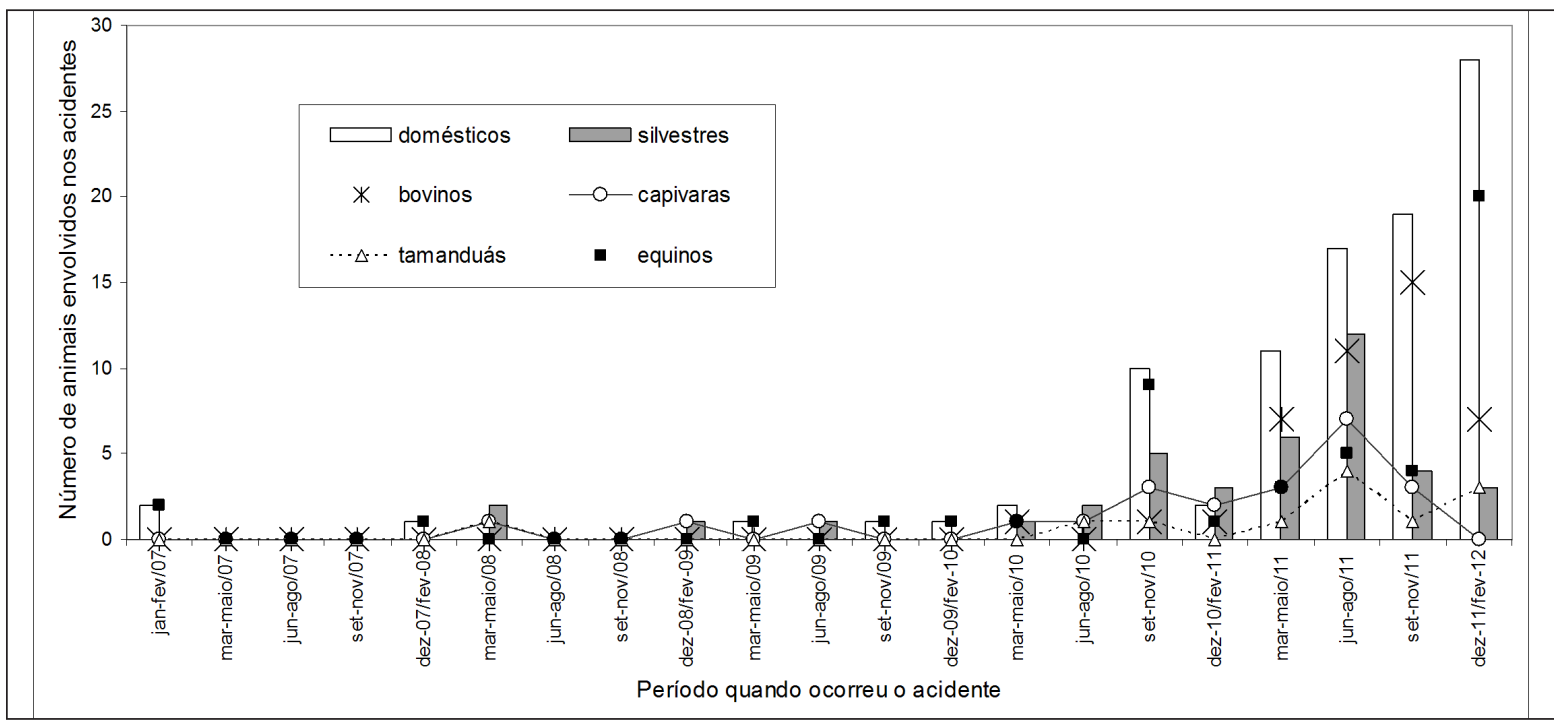

FIGURA 4 - Número de acidentes envolvendo animais (domésticos e silvestres, destacando bovinos, equinos, capivaras e tamanduás) durante cinco anos (janeiro de 2007 a fevereiro de 2012). 
1 - Acidentes com animais domésticos

A

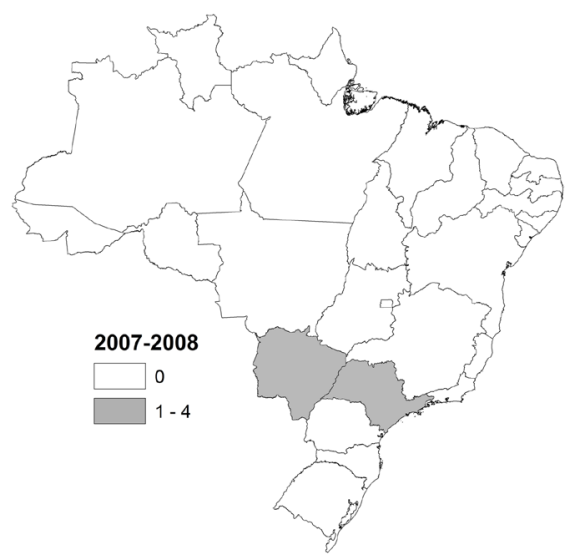

B

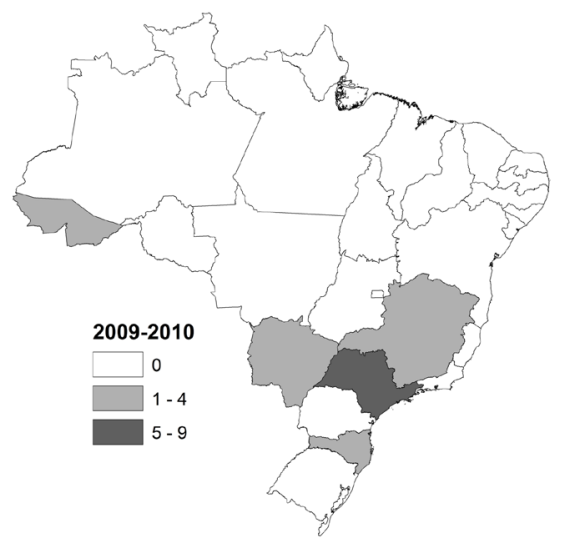

C

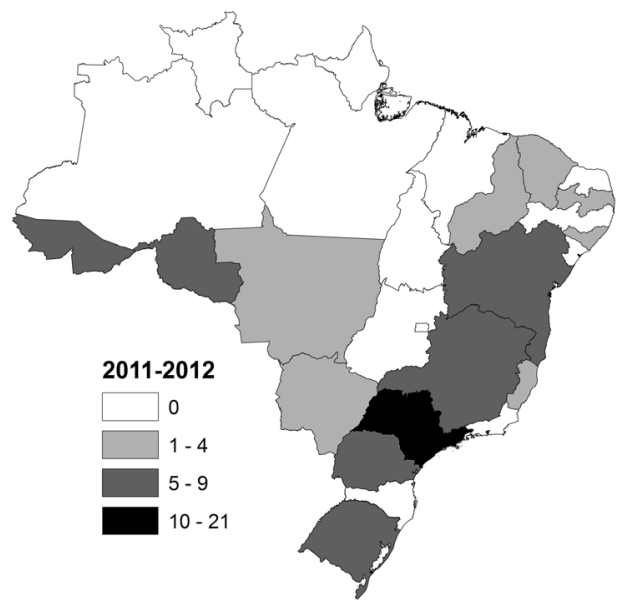

2 - Acidentes com animais silvestres
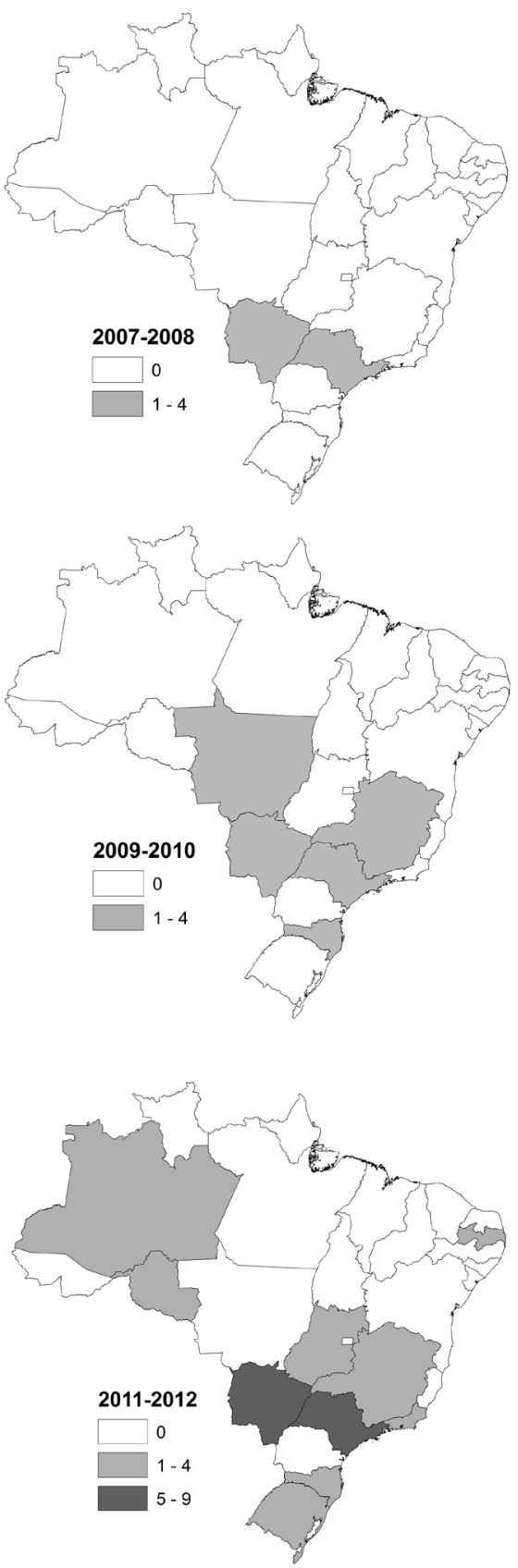

FIGURA 5 - Número de acidentes envolvendo animais domésticos e silvestres, por estado, durante três períodos: A) 2007-2008; B) 20092010 ; C) 2011-2012. 
do número de pessoas feridas, enquanto os acidentes noticiados com animais silvestres levaram mais pessoas a óbito, particularmente aqueles envolvendo capivaras (que pesam $55 \mathrm{~kg}$ em média; Verdade \& Ferraz, 2006). Além disso, acidentes envolvendo um ou mais carros foram mais noticiados, provavelmente porque acidentes trágicos chamam mais atenção da mídia. A taxa de 13 óbitos humanos por ano que registramos na mídia online do Brasil são equivalentes à média encontrada na Suécia, de 10 a 15 óbitos humanos causados por acidentes com alces (Seiler, 2005), e está abaixo dos cerca de 16 vezes mais óbitos humanos registrados nos Estados Unidos (Huijser et al., 2009). No entanto, a taxa de 0,528 óbitos/acidente encontrada no presente estudo, que indica que mais da metade dos acidentes resultam em morte, foi muito acima das taxas encontradas na Suécia $(0,003$ mortes a cada colisão com alces) e nos Estados Unidos (0,0001 mortes a cada colisão com animais). Essa análise indica a presença marcante da mídia no tema, o que demonstra a ligação evidente entre acidentes de trânsito com animais e letalidade para as pessoas. Considerando que os acidentes noticiados pela mídia online incluem apenas graves acidentes que causam comoção popular e que a produção de notícias depende de inúmeras circunstâncias de momento, além de fatores internos de tendência da própria mídia, acreditamos que nossos resultados representam superestimativas da letalidade dos acidentes e subestimativas das espécies envolvidas e dos prejuízos para a sociedade. Nesse sentido, apesar das informações que obtivemos das notícias não serem suficientes para afirmar, acidentes em estradas próximas ou dentro de Unidades de Conservação podem ser um chamariz para a mídia, particularmente quando envolvem espécies ameaçadas de extinção. Além disso, acidentes com menos prejuízo material e sem vítimas provavelmente não foram noticiados, apesar de representarem danos para os envolvidos. A morte dos animais, a perda de vidas humanas e os custos médicos com os feridos justificam medidas que evitem ou reduzam as chances de colisões entre animais e veículos.

A segurança nas rodovias é uma preocupação global por causar um grande número de mortes humanas e, por isso, a Organização das Nações Unidas (ONU) reconhece que as colisões nas rodovias são questão de saúde pública e busca mudar esse cenário com o plano global para a Década de Ação pela Segurança nas Estradas de 2011 a 2020 (UN, 2012). Para atingir as metas desse plano, a norma ISO 39001 será relevante, já que dita quais ações são necessárias para o manejo sistemático da segurança nas estradas em busca da redução das mortes e de ferimentos graves causados por acidentes rodoviários (Bliss, 2009). Nesse contexto, os acidentes rodoviários envolvendo animais contribuem com óbitos humanos e com ações específicas para reduzir esse tipo de acidente devem ser analisadas e executadas. $\mathrm{O}$ aumento da frequência de notícias publicadas, principalmente no último ano analisado, e em cada vez mais estados brasileiros, indica que o tema tem sido considerado mais relevante pela mídia eletrônica ou que mais acidentes graves têm sido registrados envolvendo animais.

A distribuição dos acidentes por estados demonstrou que em algumas regiões o tema "atropelamento de fauna" é mais relevante e que alguns estados merecem ações prioritárias para incrementar a segurança nas estradas. O estado de São Paulo concentrou a maioria dos acidentes com animais domésticos e com capivaras (Hydrochoerus hydrochaeris), enquanto Mato Grosso do Sul concentrou mais acidentes com tamanduás (Myrmecophaga tridactyla). Essas duas espécies são também comumente encontradas em monitoramentos de animais atropelados (Cáceres et al., 2010; Dornas et al., 2012), indicando que podem ser espécies relevantes para estudos que combinem questões de segurança e de conservação da biodiversidade, particularmente nos biomas onde são mais comuns; capivaras na Mata Atlântica e tamanduás no Cerrado e Pantanal. As capivaras também são foco da mídia em regiões do interior de São Paulo devido à febre maculosa e por ser uma espécie generalista que ocorre em áreas periurbanas. $\mathrm{O}$ estado de São Paulo possui a maior frota de veículos do Brasil (DENATRAN, 2012) e a maior parte de suas rodovias está sob a gerência de empresas concessionárias (CNT, 2012), que são aquelas em melhor estado de conservação (CNT, 2012). Estradas melhores possibilitam que os veículos atinjam velocidades mais altas e, junto com o maior fluxo de veículos, podem explicar a maior frequência de acidentes e ajudar a indicar medidas para reduzir esses acidentes (Jaarsma et al., 2006). Diversas organizações e empresas relacionadas a veículos e a rodovias, particularmente as empresas concessionárias, devem buscar a excelência 
em suas rodovias através do ISO 39001 e a redução das colisões entre veículos e animais deve ser uma de suas metas, sendo potenciais apoiadores de investimentos em medidas mitigadoras de acidentes entre veículos e animais. Outro setor que pode se interessar pelo tema são as empresas de seguro de vida e de veículos, já que a maior incidência de acidentes noticiados com perda total do veículo envolveu animais silvestres, particularmente capivaras. As empresas seguradoras devem avaliar o custo-benefício desses acidentes para considerar sua participação em medidas mitigadoras desses acidentes (Huijser et al., 2009). Organizações ambientalistas podem se interessar por algumas espécies de animais silvestres e colaborar na implantação de medidas para reduzir a colisão entre veículos e animais, particularmente quando os animais são espécies endêmicas ou ameaçadas de extinção como, por exemplo, tamanduá-bandeira (Myrmecophaga tridactyla), considerada uma espécie vulnerável à extinção (IUCN, 2013). A perspectiva da mídia sobre os acidentes entre veículos e animais, que busca eventos de repercussão popular, pode ser usada para campanhas publicitárias tanto das seguradoras quanto dos ambientalistas para angariar recursos financeiros próprios e para investir na mitigação dos efeitos negativos das estradas sobre a fauna.

Em geral, para evitar ou para reduzir as chances de colisões entre veículos e animais domésticos, os donos devem manter os animais em sua propriedade, fazer manutenção nas cercas, manter as porteiras fechadas e, em caso de acidente, serem responsabilizados conforme a lei. Já os acidentes envolvendo animais silvestres, para serem reduzidos, são necessárias medidas em dois sentidos: 1) alertar o motorista sobre a travessia de animais na pista; e 2) viabilizar a travessia segura dos animais (Laurance et al., 2009; Beckmann et al., 2010).

\section{1) Alertar o motorista sobre a travessia de animais na pista}

Placas e redutores de velocidade são as medidas mais comuns para alertar o usuário da rodovia sobre o maior risco de travessia de animais naquele trecho (Laurance et al., 2009; Beckmann et al., 2010). Para determinar o trecho com maior risco, os atropelamentos de animais devem ser monitorados e registrados, sendo identificados os trechos com maior frequência de atro- pelamentos (chamados de "blackspots"; Coelho et al., 2008) ou aqueles que possuem características da paisagem relacionadas a atropelamentos (Bueno et al., 2013). A maior frequência de acidentes noticiados envolveu um ou mais carros e ocorreu à noite ou de madrugada indicando que a menor visibilidade reduz a segurança nas estradas. Dessa forma, as medidas de mitigação das colisões entre veículos e animais que chamam a atenção dos motoristas devem ser visíveis no escuro ou sensíveis ao movimento, como é o caso de placas com sensores infravermelho que acendem luzes quando percebem a proximidade de algum animal (Beckmann et al., 2010). Vale a pena comentar que uma forma complementar de alertar o motorista para a aproximação de animais (ou pessoas), que conta com a contribuição do dono do veículo para a redução de acidentes, é um equipamento disponível em alguns modelos de automóvel que detecta a aproximação de animais com um sistema de formação de imagem termal de visão noturna (AUTOLIV, 2013).

\section{2) Viabilizar a travessia segura dos animais}

Para viabilizar a travessia segura dos animais são combinadas duas medidas: cercamento e passagens de fauna. A instalação de cercas pode ser feita ao longo de toda a rodovia, como na Europa, ou apenas associadas às passagens de fauna funcionando como um direcionador, conduzindo o animal até a entrada da passagem (Beckmann et al., 2010). As cercas necessitam de manutenção constante e especificações que evitem que os animais pulem a cerca ou cavem e passem por baixo desta (Mata et al., 2008; Huijser et al., 2009; Beckmann et al., 2010). Com essa medida, a colisão entre veículos e animais é reduzida e a segurança dos usuários é maximizada (Grilo et al., 2009; Huijser et al., 2009; Beckmann et al., 2010). No entanto, o uso de cercas sem ou com poucas passagens de fauna isolam as populações animais de cada margem da rodovia, reduzindo a chance de reprodução e troca gênica entre elas, aumentando a endogamia, gerando, assim, uma ameaça à extinção dessas populações por perda de diversidade genética (Balkenhol \& Waits, 2009; Corlatti et al., 2009; Laurance et al., 2009; Holderegger \& Di Giulio, 2010; Jackson \& Fahrig, 2011). Algumas modificações nas cercas são necessárias para evitar que, por falhas, o animal consiga entrar na rodovia, e não consiga sair. Como exemplo, existem os chamados 
jump-outs, que possibilitam que o animal saia, mas não entre já que é uma via única, caso ele consiga entrar na rodovia cercada (Huijser et al., 2009). Falhas em cercas que permitem a entrada de animais na rodovia em alguns trechos e dificultam a saída são um dos problemas encontrados nesse tipo de mitigação que depende de frequente manutenção (Mata et al., 2008). Além disso, em alguns casos as cercas não são a medida de mitigação mais adequada porque algumas espécies conseguem atravessá-las (cavando, pulando ou passando pela malha) ou porque algumas regiões têm características que prejudicam seu funcionamento em um período do ano, por exemplo, inundam nas estações chuvosas, fazendo com que a coluna d'água atinja a altura da rodovia, e, assim, facilitam a travessia de animais pela rodovia nesse período (Bager \& Fontoura, 2013).

A outra medida para viabilizar a travessia segura dos animais é a passagem de fauna (também chamada de ecoduto ou zoopassagem), seja por baixo da rodovia (underpasses ou culverts), seja por cima da rodovia (overpasses; Huijser et al., 2009; Beckmann et al., 2010). As passagens de fauna juntamente com alambrados para direcionar os animais para esses dutos impossibilitam que eles atravessem a pista de rolamento, ao mesmo tempo possibilitam a travessia pelos ecodutos, aumentando as chances de manter o fluxo gênico e a viabilidade das populações (Corlatti et al., 2009; Laurance et al., 2009; Holderegger \& Di Giulio, 2010). O custo-benefício da construção das passagens em relação às cercas foi estimado para colisões entre veículos e capivaras, considerando apenas o custo médio do reparo do veículo, não incluindo custos associados a ferimentos e a fatalidades humanas, reboque, assistência médica no local do acidente, investigação do acidente e à remoção da carcaça do animal da rodovia (Huijser et al., 2013). Nos trechos das rodovias paulistas estudadas, onde o número de colisões entre veículos e capivaras foi mais alto, cercas e passagens de fauna por baixo da rodovia são economicamente atrativas (Huijser et al., 2013). A alta morbidade das colisões entre veículos e capivaras indica que os custos de atendimento médico com os feridos e os prejuízos relacionados à perda de vidas humanas foram subestimados por Huijser et al. (2013). Os atropelamentos de capivaras são mais frequentes em áreas próximas de rios e com vegetação herbácea (Bueno et al., 2013).
Dessa forma, a aplicação de medidas mitigadoras nessas colisões deve ser prioridade, especialmente em trechos de rodovias onde esses acidentes são frequentes e onde as capivaras e seu hábitat estão presentes. A análise de custo-benefício mais completa foi feita por Huijser et al. (2009), sendo esta indicada para seguradoras ou empresas concessionárias de rodovias avaliarem os benefícios de evitar esses acidentes, comparando, no caso das seguradoras, o gasto de medidas preventivas com o pagamento aos segurados após a colisão veículo-animal. No caso das concessionárias, com os custos com o atendimento de emergência, remoção da carcaça e reboque do veículo envolvido no acidente. Em rodovias onde as passagens de fauna foram construídas e cercas foram instaladas, a maioria localizada na Europa e na América do Norte, pesquisadores têm avaliado sua efetividade para reduzir as colisões entre veículos e animais silvestres e para reduzir os efeitos negativos das estradas sobre as populações e as comunidades animais, mostrando que quando elas são usadas, reduzem os atropelamentos e auxiliam no aumento da conectividade entre paisagens fragmentadas por rodovias (Van der Ree et al., 2011; Lesbarrères \& Fahrig, 2012; Bager \& Fontoura, 2013; Eberhardt et al., 2013; Van der Grift et al., 2013).

Em conjunto com as medidas de mitigação dos acidentes entre veículos e animais silvestres, é indicado um trabalho de educação ambiental para conscientizar os motoristas dos riscos de colisões com animais e de como agir quando encontrar sinalizações associadas à redução de acidentes com animais. Um exemplo desse tipo de iniciativa educacional é usado na BR-040, no Rio de Janeiro, com o Projeto Caminhos da Fauna.

\section{Conclusão}

Com as notícias publicadas na internet durante cinco anos foi possível observar que a maioria dos acidentes noticiados envolveu animais domésticos, tendo como maior consequência pessoas feridas. Por outro lado, os acidentes com animais silvestres, divulgados pela mídia online, envolveram maior quantidade de pessoas mortas, particularmente aqueles com capivaras. A maioria dos acidentes foi registrada no estado de São Paulo, onde a maior parte das rodovias é gerenciada pela iniciativa 
privada com contratos de concessão. Essas empresas concessionárias, junto a seguradoras e a organizações ambientalistas, por razões distintas, poderiam apoiar financeiramente a aplicação de medidas mitigadoras para reduzir as colisões entre veículos e animais, diminuindo, assim, o número de óbitos e de feridos humanos. Para obter dados sistemáticos e em rodovias mais bem distribuídas pelo território brasileiro, são sugeridas pequenas alterações no procedimento de coleta de informações dos acidentes pela Polícia Rodoviária como, por exemplo, a distinção entre animal doméstico e animal silvestre no registro do acidente. No procedimento usualmente realizado nas rodovias privadas para fins de manutenção, poderia ser incluído o registro de informações sobre os animais atropelados detectados durante a vistoria da rodovia, incluindo o registro fotográfico com localização e data do evento.

\section{Referências}

AUTOLIV. Night vision, 2013. Disponível em: < http://www. doyouhavenightvision.com/>. Acesso em: 16 Oct. 2013.

Bager, A.; Fontoura, V. Evaluation of the effectiveness of a wildlife roadkill mitigation system in wetland habitat. Ecological Engineering, 53, 31-38, 2013.

Balkenhol, N.; Waits, L. P. Molecular road ecology: exploring the potential of genetics for investigating transportation impacts on wildlife. Molecular Ecology, 18, 4151-4164, 2009.

Beckmann, J. P.; Clevenger, A. P.; Huijser, M. P.; Hilty, J. A. Safe passages: highways, wildlife, and habitat connectivity. Washington: Island Press, 2010.

Benítez-López, A.;Alkemade, R.; Verweij, P. A. The impacts of roads and other infrastructure on mammal and bird populations: A meta-analysis. Biological Conservation, 143, 13071316, 2010.

Bliss, T. Championing safe, clean and affordable transport. ISO Focus, 6(9), 19-20, 2009.

Bueno, C.; Faustino, M. T.; Freitas, S. R. Influence of landscape characteristics on capybara road-kill on highway BR-040, southeastern Brazil. Oecologia Australis, 17(2), 130-137, 2013. doi:http://dx.doi.org/10.4257/oeco.2013.1702.11

Cáceres, N. C.; Hannibal, W.; Freitas, D. R.; Silva, E. L.; Roman, C.; Casella, J. Mammal occurrence and roadkill in two
Reconhecer a relevância dos problemas causados pelas colisões entre veículos e animais é o primeiro passo para justificar a melhoria da coleta de dados, favorecendo o embasamento da análise dos locais com maior risco de colisões. Essa atitude facilita a busca de apoio financeiro para aplicar as medidas mitigadoras mais adequadas para a redução dos acidentes, incluindo o cálculo do custo-benefício dessas medidas.

\section{Agradecimentos}

Gostaríamos de agradecer os comentários e sugestões de Cecília Bueno e de Clarissa Alves da Rosa, que contribuíram para a versão final do manuscrito.

adjacent ecoregions (Atlantic Forest and Cerrado) in southwestern Brazil. Zoologia, 27(5), 709-717, 2010.

CBEE. Atropelômetro, 2014a. Disponível em: $<$ http://cbee.ufla. br/portal/atropelometro/>. Acesso em: 02 Sep. 2014.

CBEE. Sistema Urubu é oficialmente lançado, 2014b. Disponível em: <http://cbee.ufla.br/portal/noticias.php\#15.04>. Acesso em: 02 Sep. 2014.

CNT. Pesquisa CNT de rodovias 2012, 2012. Disponível em: $<$ http://www.cnt.org.br/>. Acesso em: 16 Oct. 2013.

Coelho, I. P.;Kindel, A.; Coelho, A. V. P. Roadkills of vertebrate species on two highways through the Atlantic Forest Biosphere Reserve, southern Brazil. European Journal of Wildlife Research, 54, 689-699, 2008.

Coffin, A. W. From roadkill to road ecology: a review of the ecological effects of roads. Journal of Transport Geography, 15, 396-406, 2007.

Corlatti, L.; Hackländer, K.; Frey-Roos, F. Ability of wildlife overpasses to provide connectivity and prevent genetic isolation. Conservation Biology, 23(3), 548-556, 2009.

DENATRAN. Frota 2012, 2012. Disponível em: $<$ http://www. denatran.gov.br/frota.htm>. Acesso em: 16 Oct. 2013.

Dornas, R. A. P.; Kindel, A.; Bager, A.; Freitas, S. R. Avaliação da mortalidade de vertebrados em rodovias no Brasil. In: Bager, 
A. (Ed.). Ecologia de Estradas: tendências e pesquisas. Lavras: Ed. UFLA, p. 139-152, 2012.

Eberhardt, E.; Mitchell, S.; Fahrig, L. Road kill hotspots do not effectively indicate mitigation locations when past road kill has depressed populations. The Journal of Wildlife Management, 77(7), 1353-1359, 2013. doi:10.1002/jwmg.592

Forman, R. T. T.; Alexander, L. E. Roads and their major ecological effects. Annual Reviews in Ecology \& Systematics, 29, 207-231, 1998.

Forman, R. T. T.;Sperling, D.;Bissonette, J. A.;Clevenger, A. P.;Cutshall, C. D.;Dale, V. H.;Fahrig, L.;France, R.;Goldman, C. R.;Heanue, K.;Jones, J. A.;Swanson, F. J.;Turrentine, T.; Winter, T. C. Road ecology: science and solutions. Washington: Island Press, 2003.

Grilo, C.; Bissonette, J. A.; Santos-Reis, M. Spatial-temporal patterns in Mediterranean carnivore road casualties: Consequences for mitigation. Biological Conservation, 142, 301313, 2009.

Hanski, I. Metapopulation dynamics. Nature, 396, 41-49, 1998.

Holderegger, R.; Di Giulio, M. The genetic effects of roads: a review of empirical evidence. Basic and Applied Ecology, 11, 522-531, 2010.

Huijser, M. P.; Abra, F. D.; Duffield, J. W. Mammal road mortality and cost-benefit analyses of mitigation measures aimed at reducing collisions with capybara (Hydrochoerus hydrochaeris) in São Paulo state, Brazil. Oecologia Australis, 17(1), 129-146, 2013. doi:http://dx.doi.org/10.4257/ oeco.2013.1701.11

Huijser, M. P.; Duffield, J. W.; Clevenger, A. P.; Ament, R. J.; McGowen, P. T. Cost-benefit analyses of mitigation measures aimed at reducing collisions with large ungulates in the Unites States and Canada: a decision support tool. Ecology and Society, 14(2), 15, 2009.

IUCN. IUCN Red List of Threatened Species (Version 2013.1), 2013. Disponível em: <www.iucnredlist.org>. Acesso em: 16 October 2013.

Jaarsma, C. F.; Van Langevelde, F.; Botma, H. Flattened fauna and mitigation: Traffic victims related to road, traffic, vehicle, and species characteristics. Transportation Research Part D, 11, 264-276, 2006.

Jackson, N. D.; Fahrig, L. Relative effects of road mortality and decreased connectivity on population genetic diversity. Biological Conservation, 144, 3143-3148, 2011.
Jaeger, J. A. G.;Bowman, J.;Brennan, J.;Fahrig, L.;Bert, D.;Bouchard, J.;Charbonneau, N.;Frank, K.;Gruber, B.; von Toschanowitz, K. T. Predicting when animal populations are at risk from roads: an interactive model of road avoidance behavior. Ecological Modelling, 185, 329-348, 2005.

Lande, R. Risks of population extinction from demographic and environmental stochasticity and random catastrophes. The American Naturalist, 142(6), 911-927, 1993.

Langley, R. L.; Higgins, S. A.; Herrin, K. B. Risk factors associated with fatal animal-vehicle collisions in the United States, 1995-2004. Wilderness and Environmental Medicine, 17, 229-239, 2006.

Laurance, W. F.;Goosem, M.; Laurance, S. G. W. Impacts of roads and linear clearings on tropical forests. Trends in Ecology and Evolution, 24(12), 659-669, 2009.

Lesbarrères, D.; Fahrig, L. Measures to reduce population fragmentation by roads: what has worked and how do we know? Trends in Ecology and Evolution, 27(7), 374-380, 2012.

Mata, C.; Hervás, I.; Herranz, J.; Suárez, F.; Malo, J. E. Are motorway wildlife passages worth building? Vertebrate use of road-crossing structures on a Spanish motorway. Journal of Environmental Management, 88, 407-415, 2008.

Murcia, C. Edge effects in fragmented forests: implications for conservation. Trends in Ecology and Evolution, 10(2), 58-62, 1995.

Purvis, A.; Gittleman, J. L.; Cowlishaw, G.; Mace, G. M. Predicting extinction risk in declining species. Proceedings of the Royal Society of London - B, 267, 1947-1952, 2000. doi:10.1098/rspb.2000.1234

Rosa, C. A.; Bager, A. Review of the factors underlying the mechanisms and effects of roads on vertebrates. Oecologia Australis, 17(1), 6-19, 2013.

Seiler, A. Trends and spatial patterns in ungulate-vehicle collisions in Sweden. Wildlife Biology, 10(4), 301-313, 2004.

Seiler, A. Predicting locations of moose-vehicle collisions in Sweden. Journal of Animal Ecology, 42, 371-382, 2005.

Seiler, A.; Helldin, J.-O. Mortality in wildlife due to transportation. In: Davenport, J.; Davenport, J. L. (Eds.). The ecology of transportation: managing mobility for the environment. Dordrecht: Springer, p. 165-189, 2006.

Taylor, B. D.; Goldingay, R. L. Roads and wildlife: impacts, mitigation and implications for wildlife management in Australia. Wildlife Research, 37, 320-331, 2010. 
UN. Improving global road safety (Report). United Nations, 2012. Disponível em: <http://www.un.org/en/ga/search/ view_doc.asp?symbol=\%20A/RES/66/260>. Acesso em: 11 Out. 2013.

Van der Grift, E. A.; Van der Ree, R.; Fahrig, L.; Findley, S.; Houlahan, J.; Jaeger, J. A. G.; Klar, N.; Madriñan, L. F.; Olsen, L. Evaluating the effectiveness of road mitigation measures. Biodiversity and Conservation, 22, 425-448, 2013.
Van der Ree, R.; Jaeger, J. A. G.; Van der Grift, E. A.; Clevenger, A. P. Effects of roads and traffic on wildlife populations and landscape function: Road Ecology is moving toward larger scales. Ecology and Society, 16(1), 48, 2011.

Verdade, L. M.; Ferraz, K. M. P. M. B. Capybaras in an anthropogenic habitat in southeastern Brazil. Brazilian Journal of Biology, 66(1B), 371-378, 2006. 